\title{
Arsenic Determination in Pharmaceutical Grade Barium Sulfate using Direct Solid Sampling Electrothermal Atomic Absorption Spectrometry
}

\author{
Rodrigo C. Bolzan, ${ }^{a}$ Diogo P. de Moraes, ${ }^{b}$ Julio Cezar P. de Mattos, ${ }^{b}$ Valderi L. Dressler ${ }^{b}$ \\ and Érico M. de Moraes Flores*,b \\ ${ }^{a}$ Departamento de Ciências da Saúde, Universidade Regional Integrada do Alto Uruguai e das \\ Missões, Campus de Frederico Westphalen, 98400-000 Frederico Westphalen-RS, Brazil \\ ${ }^{b}$ Departamento de Química, Universidade Federal de Santa Maria, \\ 97105-900 Santa Maria-RS, Brazil
}

\begin{abstract}
Um método para determinação de arsênio em $\mathrm{BaSO}_{4}$ por espectrometria de absorção atômica com aquecimento eletrotérmico e introdução de amostras sólidas (SoS-ET AAS) é descrito. Foram avaliados dois sistemas de correção de fundo (BG), deutério e efeito Zeeman (Z). Com o uso combinado de hidrogênio e Pd o BG foi diminuído. Resultados exatos e precisos foram obtidos usando Z-SoS-ET AAS. O desvio padrão relativo usando Z-SoS-ET AAS foi menor que $9,5 \%$. O limite de detecção foi $0,005 \mu \mathrm{g} \mathrm{g}^{-1}$ e a massa característica foi $25,4 \mathrm{pg}$. Os resultados foram comparados com os obtidos usando o método de preparo de amostras sugerido pela Farmacopeia Europeia, com determinação usando espectrometria de emissão ótica e espectrometria de massas, ambos com plasma indutivamente acoplado, porém os resultados foram cerca de $20 \%$ menores. Vantagens como simplicidade, elevada frequência de determinações e boa exatidão foram obtidos em comparação com o método descrito na farmacopeia.
\end{abstract}

A method for arsenic determination in pharmaceutical grade $\mathrm{BaSO}_{4}$ by solid sampling electrothermal atomic absorption spectrometry (SoS-ET AAS) is described. Two background (BG) correction systems, deuterium and Zeeman-effect $(Z)$, were evaluated. Background was decreased by using hydrogen combined with Pd. Accurate and precise results were obtained using Z-SoS-ET AAS. Relative standard deviation using Z-SoS-ET AAS was lower than 9.5\%. Limit of detection was $0.005 \mu \mathrm{g} \mathrm{g}^{-1}$ and characteristic mass was $25.4 \mathrm{pg}$. Results were also compared with those obtained using the preparation method suggested by European Pharmacopoeia for $\mathrm{BaSO}_{4}$ followed by determination using inductively coupled plasma optical emission spectrometry and inductively coupled plasma mass spectrometry. Results were around $20 \%$ lower than results obtained using the proposed method. Some advantages as simplicity, higher sample throughput were found when compared with the official method currently described in pharmacopoeia.

Keywords: arsenic determination, solid sampling, barium sulfate, electrothermal atomic absorption spectrometry, pharmaceutical analysis

\section{Introduction}

Barium sulfate is a raw material widely used in pharmaceutical industry for production of suspensions for radiographic templates. In view of presence of some elements in $\mathrm{BaSO}_{4}$, specially those classified as heavy metals by official pharmacopoeias, their routine control in pharmaceutical industry is mandatory in many countries. ${ }^{1,2}$

Arsenic is one of the most relevant elements in view of

*e-mail: flores@quimica.ufsm.br its toxicology potential..$^{3-5}$ This element is classified as a class "I" human carcinogen by World Health Organization and it has been associated with skin, lung, bladder, kidney, and liver cancers. ${ }^{6}$ Therefore, As is included in routine analysis of limit test for heavy metals, for example, in the United States and European Pharmacopoeias. ${ }^{1,2}$ The recommended method in pharmacopoeias for heavy metals determination is the classical reaction with thioacetamide or hydrogen sulfide in weakly acidic medium. The test should be also suitable for the determination of arsenic, but consistent results could be achieved only for relatively high As concentrations. ${ }^{1,2}$ 
According to pharmacopoeical recommendations the limit test for heavy metals should be performed by extraction in open vessels with diluted acid solution before the reaction with sulfide. ${ }^{1,2}$ However, this procedure is prone to several drawbacks as (i) risks of contamination and analyte losses; (ii) limit test is not specific for As, but gives only general information based on color appearance for a group of elements; (iii) lack of accuracy and sensitivity; (iv) time consuming, and $(v)$ use of unstable reagents.

In addition to the general limit test, European Pharmacopoeia recommends two specific tests for arsenic in $\mathrm{BaSO}_{4}$, based on the reaction with potassium iodine or arsine generation after a laborious sample preparation step. ${ }^{2}$ In this case, the maximum As content has been set as $2 \mu \mathrm{g} \mathrm{g}^{-1}$ for pharmaceutical grade $\mathrm{BaSO}_{4}$. This test also presents some limitations as: only qualitative information is supplied, subjective interpretation is needed and high contamination risks. Furthermore, in the specific case of $\mathrm{BaSO}_{4}$, this substance is practically insoluble in water and also in mineral acids making conventional wet chemistry digestion a laborious procedure.

On the other hand, electrothermal atomic absorption spectrometry (ET AAS) is a well established technique for As determination in several kinds of samples. ${ }^{7,8}$ The conventional application of this technique involves sample digestion steps, usually ashing or acid digestion, which are time consuming and prone to contamination or analyte losses. ${ }^{9}$ However, direct solid sampling electrothermal atomic absorption spectrometry (SoS-ET AAS) has been proposed as an alternative to the conventional methods of analysis where problems related to unsuitable limits of detection (LOD) or difficulties of sample digestion are present. ${ }^{9,10}$ This technique has been also applied for trace element determination at low levels in a wide variety of samples. ${ }^{9-15}$ Some advantages has been cited for SoS-ET AAS as reduced sample pretreatment and hence increased sample throughput, low contamination risk (an essential requirement when trace levels of metals must be determined), lower risks of analyte losses during the sample pretreatment, and the use of corrosive and hazardous chemicals is avoided. ${ }^{9,16}$

The use of SoS-ET AAS for As determination at low levels in $\mathrm{BaSO}_{4}$ could present advantages over the techniques based on wet analysis, considering the matrix chemical characteristics described elsewhere. However, the sulfate matrix is often a source of interferences in ET AAS. Depending on the analyte and temperature parameters, sulfate may cause both spectral and chemical interferences. ${ }^{17}$ Moreover, the presence of relatively low amounts of alkaline and alkaline earth metal sulfates can cause high background (BG) signals. ${ }^{18-20}$ Thermal decomposition of sulfates often produces compounds that cause structured or broad-band unspecific BG signals over a wide spectral range. Instruments equipped with deuterium $\left(\mathrm{D}_{2}\right)$ BG correction systems are commonly used in routine and research laboratories. However, some errors have been reported when using deuterium systems and $\mathrm{BG}$ correction based on Zeeman-effect $(\mathrm{Z})$ has been more successfully applied for complex matrices analysis. ${ }^{21}$ With the application of chemical modifiers and careful adjustment of temperature parameters in some specific cases deuterium BG correction could be successfully used, providing performance similar to Zeeman-effect based systems. ${ }^{21-23}$ On the other hand, hydrogen addition shows to be effective to reduce the $\mathrm{BG}^{24}$ or to improve the performance of $\mathrm{Pd}$ as chemical modifier ${ }^{25}$ making feasible the analysis by ET AAS.

In the literature only one study was found related to As determination in a similar matrix used in the present work. ${ }^{26}$ Authors demonstrated the feasibility of $\mathrm{D}_{2}$-SoS-ET AAS for trace element analysis in barytes (a mineral basically constituted by $\mathrm{BaSO}_{4}$ ). They found also that concentrated nitric acid could be used as chemical modifier for As determination. However, in spite of good results found for other elements, some figures of merit for As (accuracy, LOD and sample mass interval) were not presented. Moreover, calibration was performed using solid reference materials having different matrix composition (soil or sediments).

Based on these considerations, in this work a comparison of the performance for two instruments equipped with deuterium or Zeeman-effect BG correction systems was performed in order to develop a method for As determination in pharmaceutical grade $\mathrm{BaSO}_{4}$ by SoS-ET AAS. Operational parameters were evaluated in order to achieve feasible calibration using aqueous standards. The influence of palladium combined with hydrogen addition during pyrolysis step was also investigated. Spiked samples were used to check the accuracy. However, no certified reference material with similar composition for $\mathrm{BaSO}_{4}$ is available and results were compared with those obtained by inductively coupled plasma optical emission spectrometry (ICP OES) and inductively coupled plasma mass spectrometry (ICP-MS) after the extraction procedure described in European Pharmacopoeia.

\section{Experimental}

\section{Instrumentation and operating conditions}

Arsenic determination was carried out using a Model AAS 5 EA atomic absorption spectrometer equipped with a deuterium BG correction system (Analytik Jena, Jena, 
Germany) and a Model AAS ZEEnit 60 atomic absorption spectrometer (Analytik Jena) equipped with Zeeman-effect $\mathrm{BG}$ correction system. Both equipments used transversely heated graphite heating and hollow cathode lamps for arsenic (8 mA, wavelength $193.7 \mathrm{~nm}$, spectral bandpass $0.8 \mathrm{~nm}$ ). Spectrometers were equipped with a special device for manual direct introduction of solid samples into the graphite furnace (Models SSA-5 and SSA-6Z for $\mathrm{D}_{2}$ - and Z-SoSET AAS, respectively, Analytik Jena). Pyrolytic coated graphite tubes (Part Nr. 407-A81.011 and 407-152.023, for $\mathrm{D}_{2}$ - and Z-SoS-ET AAS, respectively, Analytik Jena) were used throughout. Integrated absorbance was used for signal evaluation with an integration time of $10 \mathrm{~s}$. Argon 99.996\% of purity (White Martins-Praxair, SP, Brazil) was used for SoS-ET AAS measurements and also for ICP-MS and ICP OES determinations. Hydrogen $(99.999 \%$, White Martins-Praxair) was used during pyrolysis step for the determinations by ET AAS. A Model M2P microbalance (Sartorius, Göttingen, Germany) with a resolution of $1 \mu \mathrm{g}$ was used for weighing the samples. The heating program for arsenic determination is in Table 1.

Table 1. Graphite furnace heating program for arsenic determination in barium sulfate by Z-SoS-ET AAS

\begin{tabular}{|c|c|c|c|c|c|}
\hline & $\mathrm{T} /{ }^{\circ} \mathrm{C}$ & $\begin{array}{l}\text { Ramp / } \\
\left({ }^{\circ} \mathrm{C} \mathrm{s}^{-1}\right)\end{array}$ & time / s & $\begin{array}{c}\text { Inert gas / } \\
\left.(\mathrm{L} \mathrm{min})^{-1}\right)\end{array}$ & $\begin{array}{c}\text { Hydrogen / } \\
\left(\mathrm{L} \mathrm{min}^{-1}\right)\end{array}$ \\
\hline Drying 1 & 110 & 15 & 30 & 2 & - \\
\hline Drying 2 & 120 & 15 & 15 & 2 & - \\
\hline Pyrolysis & 1300 & 400 & 20 & 2 & 0.5 \\
\hline Auto zero & 1300 & 0 & 6 & - & - \\
\hline Atomization & 2200 & 3000 & 10 & - & - \\
\hline Clean out & 2600 & 3000 & 4 & 2 & - \\
\hline
\end{tabular}

For the comparison of results sample digestion (extraction) was performed in glass vessels using a water bath according to the procedure described in $5^{\text {th }}$ edition of European Pharmacopoeia $\left(\mathrm{HNO}_{3}\right.$ digestion). ${ }^{2}$ Extracts were analyzed by the semi-quantitative recommended procedure by arsine generation and also by ICP OES and ICP-MS.

Determinations by ICP OES were performed using a Model Optima 4300 DV inductively coupled plasma optical emission spectrometer (Perkin Elmer, Shelton, USA), equipped with a cyclonic spray chamber (Glass Expansion, Inc., West Melbourne, Australia), a pneumatic nebulizer GemCone-type, and an alumina injector tube ( $2 \mathrm{~mm}$ i.d.). The operating conditions were: radiofrequency power of $1.4 \mathrm{~kW}$, principal plasma gas flow rate of $15 \mathrm{~L} \mathrm{~min}^{-1}$, nebulizer gas flow rate of $0.6 \mathrm{~L} \mathrm{~min}^{-1}$ and auxiliary gas flow rate of $0.2 \mathrm{~L} \mathrm{~min}^{-1}$. Selected spectral line was $188.979 \mathrm{~nm}$ and peak area was used for signal acquisition using three points per peak and two points for BG correction. All measurements were carried out using plasma axial view.

Determinations by ICP-MS were performed using an inductively coupled plasma mass spectrometer (PerkinElmer Sciex, Model Elan DRC II, Thornhill, Canada), equipped with a concentric nebulizer (Meinhard Associates, Golden, USA), a cyclonic spray chamber (Glass Expansion, Inc., West Melbourne, Australia) and a quartz torch with a quartz injector tube (2 $\mathrm{mm}$ i.d.). Instrumental performance optimization, including nebulizer gas flow rate, ion lens voltage and torch alignment, was carried out following the instructions of the manufacturer. The operating conditions were: radiofrequency power of 1.3. $\mathrm{kW}$, main plasma gas flow rate of $15 \mathrm{~L} \mathrm{~min}^{-1}$, auxiliary gas flow rate of $1.2 \mathrm{~L} \mathrm{~min}^{-1}$, and nebulizer gas flow rate of $1.12 \mathrm{~L} \mathrm{~min}^{-1}$. Single ion monitoring at $m / z, 75$ was used.

\section{Samples and reagents}

Powdered pharmaceutical grade $\mathrm{BaSO}_{4}$ samples (purity higher than $97.5 \%$ ) were purchased from pharmaceutical industries (samples "A" to "E") and they were previously dried using a conventional oven $\left(105^{\circ} \mathrm{C}\right.$ by $\left.2 \mathrm{~h}\right)$. The particle size distribution of $\mathrm{BaSO}_{4}$ samples were checked by optical microscopy. Sample "A" was used for initial tests and adjustment of the heating program by ET AAS. Distilled and deionized water was further purified using a Milli-Q system (Millipore Corp., Bedford, USA). Reference solutions were daily prepared by serial dilution of stock As solutions $\left(1 \mathrm{~g} \mathrm{~L}^{-1} \mathrm{As}\right.$ in $\left.2 \% \mathrm{HNO}_{3}\right)$. Concentrated nitric acid used for sample digestion/extraction was doubly distilled in a sub-boiling system (Milestone, Model duoPUR 2.01 E, Bergamo, Italy). All reagents were of analytical grade (Merck, Darmstadt, Germany).

\section{Procedures}

For the proposed procedure by SoS-ET AAS test samples of barium sulfate were weighted directly on the graphite platform and transferred to the graphite tube using a manual device for solid introduction. In order to adjust the temperature parameters for As determination by SoS-ET AAS with deuterium and Zeeman-effect BG correction systems, pyrolysis and atomization curves were established with temperatures ranging from 900 to $1700^{\circ} \mathrm{C}$ and from 1800 to $2500{ }^{\circ} \mathrm{C}$, respectively. For Z-SoS-ET AAS only 2-field mode was used (field strength $0.8 \mathrm{~T}$ ). The effectiveness of $\mathrm{Pd}(5 \mu \mathrm{g})$, hydrogen addition $\left(0.5 \mathrm{~L} \mathrm{~min}^{-1}\right)$ during pyrolysis step as chemical modifiers and also the combination of both were evaluated. The chemical modifier amount was established according to literature data. ${ }^{27}$ 
Modifier solution was added directly on the solid sample after weighing on the graphite platform. In addition, the investigation of the optimum sample mass range for As determination was performed using a method similar to the described by Belarra et al. ${ }^{28}$ Blanks were evaluated by simulating the same individual steps (weighing, transport, and modifier addition) using an empty platform. Arsenic reference solutions were prepared by serial dilution with water of $1000 \mathrm{mg} \mathrm{mL}^{-1}$ sodium arsenate stock solution (Merck, Catalog number 1.09939). Recovery tests were performed by adding arsenic reference solution $(20 \mu \mathrm{L})$ to the solid $\mathrm{BaSO}_{4}$ after sample weighing.

For As determination by ICP OES and ICP-MS, samples were previously treated using the procedure described in $5^{\text {th }}$ edition of European Pharmacopoeia. ${ }^{2}$ Barium sulfate $(0.5 \mathrm{~g})$ was transferred to glass vessels and $2 \mathrm{~mL}$ of concentrated $\mathrm{HNO}_{3}$ and $30 \mathrm{~mL}$ of water were added. Vessels were heated by $2 \mathrm{~h}$ in a water-bath. After filtration of solution $1 \mathrm{~mL}$ of concentrated $\mathrm{H}_{2} \mathrm{SO}_{4}$ was added and solution was evaporated to dryness and further heated until white fumes formation. After cooling, digests were diluted with $10 \%$ (v/v) $\mathrm{H}_{2} \mathrm{SO}_{4}$ and water up to $20 \mathrm{~mL}$. This solution was also analyzed by the procedure using arsine generation. ${ }^{2}$

In order to check the accuracy, As determination by neutron activation analysis (NAA) was performed by irradiating $\mathrm{BaSO}_{4}$ sample "E" under neutron flow of $4.5 \times 10^{12} \mathrm{n} \mathrm{cm}^{-2} \mathrm{~s}^{-1}$, by $8 \mathrm{~h}$. Before five days, gamma activity measurements were performed in a hyperpure Ge detector linked to a spectrometer. The radioisotope measured was ${ }^{76} \mathrm{As}$ at $559 \mathrm{keV}$.

\section{Statistical analysis}

Data were evaluated using analysis of variance. TukeyKramer multiple comparisons test $(\mathrm{p}<0.05)$ was applied.

\section{Results and Discussion}

Pyrolysis and atomization profiles for arsenic in barium sulfate

Initially, the attempts to establish pyrolysis and atomization curves for As in barium sulfate without chemical modifier were not successful, mainly when using $\mathrm{D}_{2}$-SoS-ET AAS. Baseline disturbance caused by relatively high BG signal did not allow the acquisition of reliable data using both BG systems. Palladium has been used in view of its effectiveness for the determination of arsenic in a wide variety of samples..$^{29}$ Therefore, palladium solution (correspondent to $5 \mu \mathrm{g}$ ) was used as chemical modifier and it was added directly on the solid sample after the weighing on the graphite platform. However, using Pd the signals for As using $\mathrm{D}_{2}$-SoS-ET AAS (Figure 1A) did not return completely to the baseline within $10 \mathrm{~s}$ of integration time (pyrolysis and atomization temperatures were set at 1300 and $2200{ }^{\circ} \mathrm{C}$, respectively). Even using Z-SoS-ET AAS (Figure 1B) the BG signals were relatively high (about 0.6 in peak height) and overcorrection was observed impairing feasible determination of As. With the increase of atomization temperature up to $2500^{\circ} \mathrm{C}$ the intensity of BG was also increased and a signal depression about $50 \%$ (for $2500^{\circ} \mathrm{C}$ ) was observed using both BG correction systems.
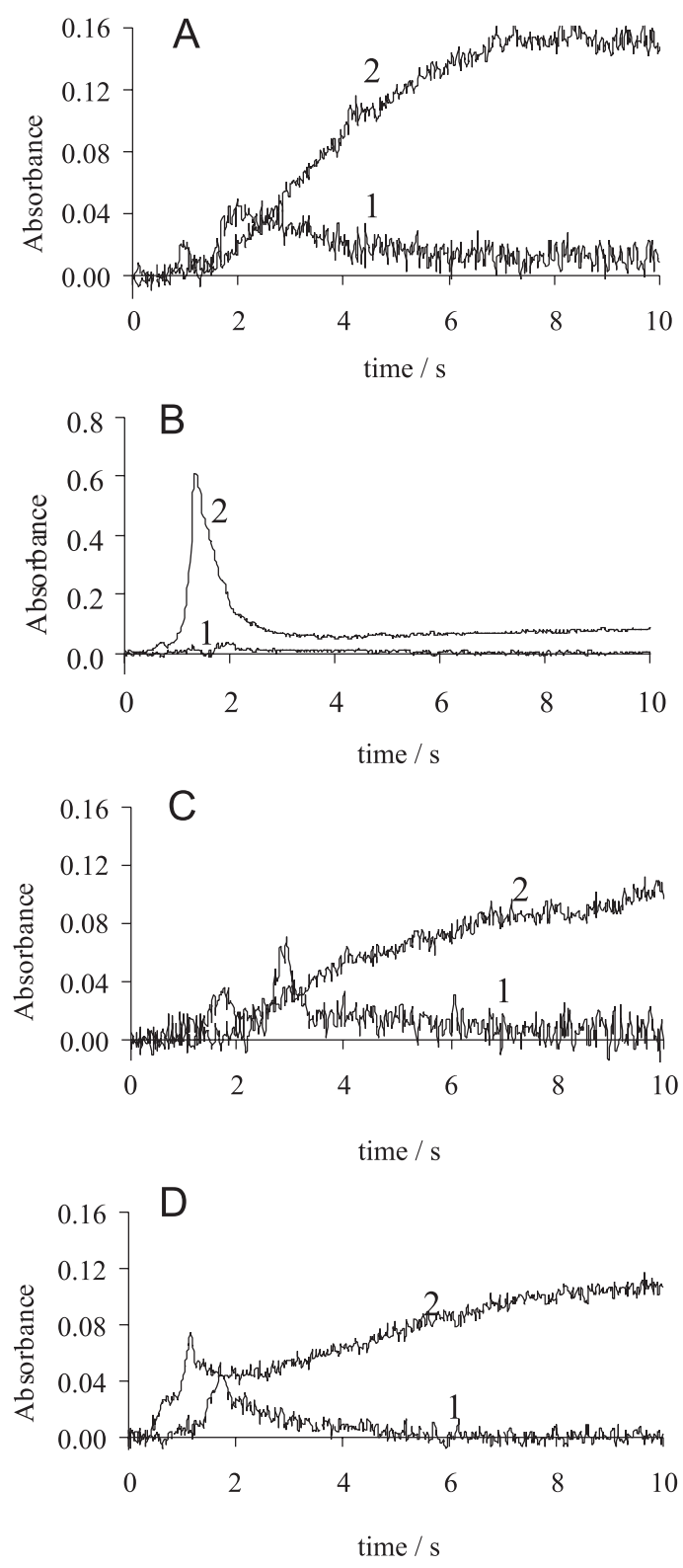

Figure 1. Analytical [1] and BG [2] signals for arsenic in barium sulfate by $\mathrm{D}_{2}$-SoS-ET AAS (A and C) and Z-SoS-ET AAS (B and D). Pyrolysis was set at $1300{ }^{\circ} \mathrm{C}$ and atomization at $2200{ }^{\circ} \mathrm{C}(5 \mu \mathrm{g}$ Pd was added). $\mathrm{C}$ and D: addition of $0.5 \mathrm{~L} \mathrm{~min}^{-1}$ hydrogen. Sample masses were $0.344 \mathrm{mg}$ (A); $0.322 \mathrm{mg}$ (B); $0.380 \mathrm{mg}$ (C); $0.261 \mathrm{mg}$ (D). 
In a previous work it was found that $64 \%$ of the barium sulfate mass remained in the platform even with pyrolysis temperature of $1500{ }^{\circ} \mathrm{C}$ and the residual matrix vaporized concomitantly with the analyte during atomization step. ${ }^{30}$ This is compatible with the thermal decomposition of $\mathrm{BaSO}_{4}$ yielding $\mathrm{BaO}, \mathrm{SO}_{2}$ and $\mathrm{O}_{2}$, at temperatures prior the melting point of barium sulfate $\left(1580^{\circ} \mathrm{C}\right) .^{31,32}$ Background signals could be originated by molecules as $\mathrm{C}_{\mathrm{n}} \mathrm{S}_{\mathrm{m}}$ (with $\mathrm{n}>\mathrm{m}$ ) formed in the gas phase at high temperatures, which yields diffuse bands from 187 to $230 \mathrm{~nm}$ region. ${ }^{19,20}$ Depending on the BG intensity it can not be efficiently compensated, mainly when using deuterium BG correction system. In addition, thermal treatment of metal sulfates could cause the generation of the correspondent metal sulfides and also elemental sulfur with consequent analyte losses and/or signal depression. ${ }^{33}$ Therefore, owing the ineffectiveness of Pd alone to overcome the interferences, gaseous hydrogen was introduced during the pyrolysis step in order to minimize the matrix effects. The addition of hydrogen has been proposed for pre-reduction of $\mathrm{Pd}$ modifier on the surface of graphite tube yielding metallic $\mathrm{Pd}$ in order to increase its efficiency. ${ }^{34}$ Contrarily to $\mathrm{Cr}$ determination, in this matrix ${ }^{30}$ the use of chemical modifier and hydrogen addition were necessary due to the high matrix interference observed in the selected wavelength for As. Analytical signals for As in $\mathrm{BaSO}_{4}$ with palladium and also hydrogen addition during pyrolysis step showed better profile and lower BG signals using both correction systems, specially for Z-SoS-ET AAS (Figures 1C and 1D). With the atomization temperature set at $2200{ }^{\circ} \mathrm{C}$, the As signal was completely integrated in $10 \mathrm{~s}$ and no overcorrection was observed for the determinations using $\mathrm{D}_{2}$ - and Z-SoS-ET AAS.

Therefore, pyrolysis and atomization curves for solid barium sulfate were established with palladium and also with hydrogen addition during pyrolysis step. Figure 2A shows the profile of pyrolysis curve using Z-SoS-ET AAS. The maximum temperature without As losses was $1300{ }^{\circ} \mathrm{C}$. For the atomization curve (Figure 2B) arsenic signals produced a slight increase from 2000 to $2200{ }^{\circ} \mathrm{C}$. At $2200{ }^{\circ} \mathrm{C}$ better analytical signals considering the BG intensity, peak shape and precision (Figures 1D and 2B) were obtained. In spite of apparently higher As signal at $2400{ }^{\circ} \mathrm{C}$ (Figure 2B), intense BG signals (about 0.7 in peak height), causing overcorrection effect were observed with consequent overestimated results. Similar curve profiles were found using $\mathrm{D}_{2}$ - and Z-SoS-ET AAS. With the use of $\mathrm{Pd}$ and hydrogen the profile for pyrolysis and atomization curves using $\mathrm{BaSO}_{4}$ were analogous to those for As aqueous standards in the same conditions. Then, the selected temperatures for subsequent studies were 1300 and $2200{ }^{\circ} \mathrm{C}$ for pyrolysis and atomization, respectively. These temperature parameters are in agreement with those previously reported for As determination using Pd as chemical modifier (without hydrogen addition). ${ }^{35}$
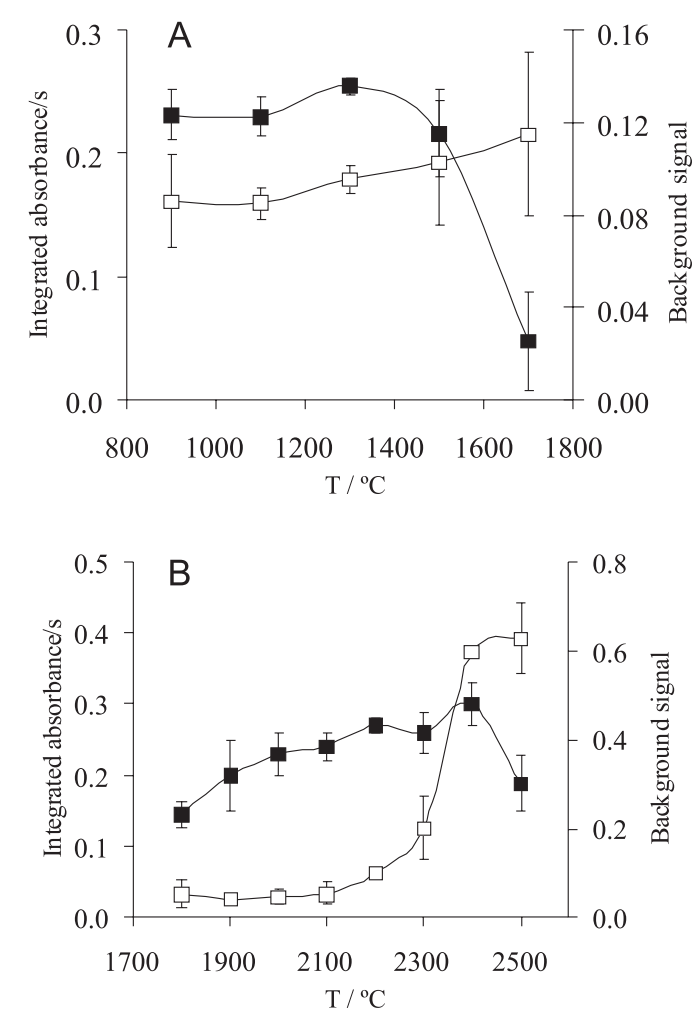

Figure 2. Pyrolysis (A) and atomization (B) curves for As in $\mathrm{BaSO}_{4}$ using Z-SoS-ET AAS: $\square$ analytical and $\square$ BG (peak height) signals. Pyrolysis set at $1300{ }^{\circ} \mathrm{C}$ and atomization at $2200{ }^{\circ} \mathrm{C}$. Vertical bars are the correspondent standard deviations $(\mathrm{n}=3)$. Barium sulfate mass was $0.27 \pm 0.03 \mathrm{mg}, 5 \mu \mathrm{g} \mathrm{Pd}, 0.5 \mathrm{~L} \mathrm{~min}^{-1}$ hydrogen.

\section{Behavior of matrix during thermal treatment}

In order to evaluate the effect of Pd and hydrogen addition on the thermal behavior of barium sulfate during pyrolysis step, the variation of sample mass was determined with increasing of pyrolysis temperatures. The dependence of mass loss with the temperature is shown in Figure 3. The curve of sample loss without $\mathrm{Pd}$ or $\mathrm{H}_{2}$ was very similar to the curve using only Pd. For both conditions, up to $1300^{\circ} \mathrm{C}$, the mass of barium sulfate presented a small decrease. However, with higher temperatures the loss increased quickly achieving about $20 \%$ at $1500{ }^{\circ} \mathrm{C}$ and around $50 \%$ at $1800^{\circ} \mathrm{C}$. Using Pd the shape of mass loss curve in the range of temperatures between 1600 and $1800{ }^{\circ} \mathrm{C}$ was similar for both conditions (Figure 3). Palladium and hydrogen probably interfere in thermal decomposition of $\mathrm{BaSO}_{4}$ preventing the formation of sulfur species in the gas phase which can result in diffuse bands from 187 to $230 \mathrm{~nm}$ region. ${ }^{19,20}$ 


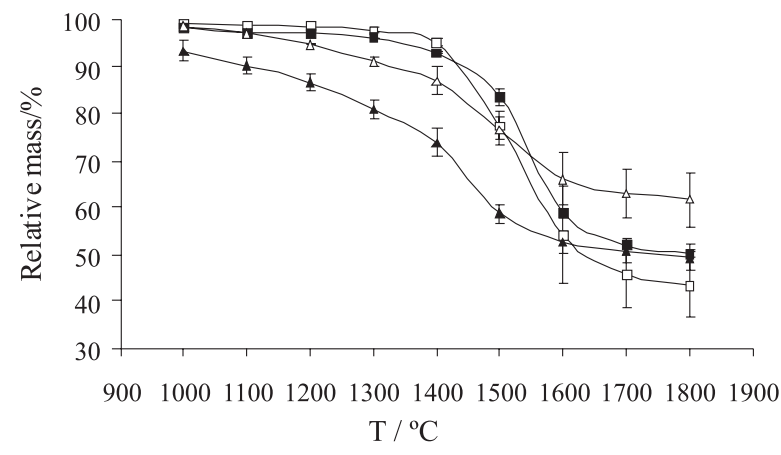

Figure 3. Relative mass loss of barium sulfate $(2.5 \pm 0.1 \mathrm{mg})$ after heating at temperatures between 1000 and $1800{ }^{\circ} \mathrm{C}$. Argon flow rate was $2.0 \mathrm{~L} \mathrm{~min}^{-1}$; $\square$ without $\mathrm{Pd}$ or $\mathrm{H}_{2}$ addition; $\boldsymbol{\square}=10 \mu \mathrm{g}$ of $\mathrm{Pd}$; $\triangle=0.5 \mathrm{~L} \mathrm{~min}^{-1} \mathrm{H}_{2} ; \boldsymbol{\Delta}=10 \mu \mathrm{g}$ of $\mathrm{Pd}$ and $0.5 \mathrm{~L} \mathrm{~min}^{-1} \mathrm{H}_{2} \mathrm{n}=3$.

When only hydrogen was used as chemical modifier the decrease of sample mass in temperatures higher than $1500^{\circ} \mathrm{C}$ was less pronounced (Figure 3) although at temperatures between 1200 and $1400^{\circ} \mathrm{C}$ the decrease of sample mass was bigger than at the conditions without chemical modifier or in the presence of Pd. When Pd was used with $\mathrm{H}_{2}$ the shape of sample loss curve was similar with to the curve when only $\mathrm{H}_{2}$ was used (Figure 3). However, for all the investigated temperatures losses were observed in a higher intensity (about 5 to $15 \%$ ). Probably, the use of palladium with $\mathrm{H}_{2}$ could be associated with the increase of mass losses from the platform.

In the present work the pyrolysis temperature was set at $1300{ }^{\circ} \mathrm{C}$ using $\mathrm{Pd}$ and $\mathrm{H}_{2}$ (Figure 2A). In these conditions $\mathrm{BG}$ signals were relatively lower than those using only Pd as shown in Figure 1 . At $1300{ }^{\circ} \mathrm{C}$ the loss of $\mathrm{BaSO}_{4}$ using $\mathrm{Pd}$ and $\mathrm{H}_{2}$ was $15 \%$ higher when compared with the same condition without $\mathrm{H}_{2}$ (Figure 3). Then, after the pyrolysis step lower $\mathrm{BaSO}_{4}$ remained in the platform and this fact could explain the strong reduction of BG signals using both correctors ( $\mathrm{D}_{2}$ and Zeeman-effect) as shown in Figure 1.

\section{Sample mass range}

The maximum sample mass that could be introduced in the graphite tube under optimized conditions was investigated and this procedure was performed similarly to that described by Belarra et al. ${ }^{28}$ For both atomizers sample masses between 0.05 and $1 \mathrm{mg}$ were tested. However, with sample masses higher than 0.55 and $0.8 \mathrm{mg}$ for $\mathrm{D}_{2}-$ and Z-SoS-ETAAS, respectively, intense BG signals that could be not compensated by both correction systems were observed (error messages related to excessive BG were displayed by the software).

For tests by $\mathrm{D}_{2}$-SoS-ETAASS the mass curve from 0.05 to $0.55 \mathrm{mg}$ presented an unusual profile (Figure 4) and no mass interval with constant absorbance signal/sample mass ratio was identified. By evaluating the statistical data
(Table 2), it was observed that mass values from B- to C-block or from D- to F-block could be used.

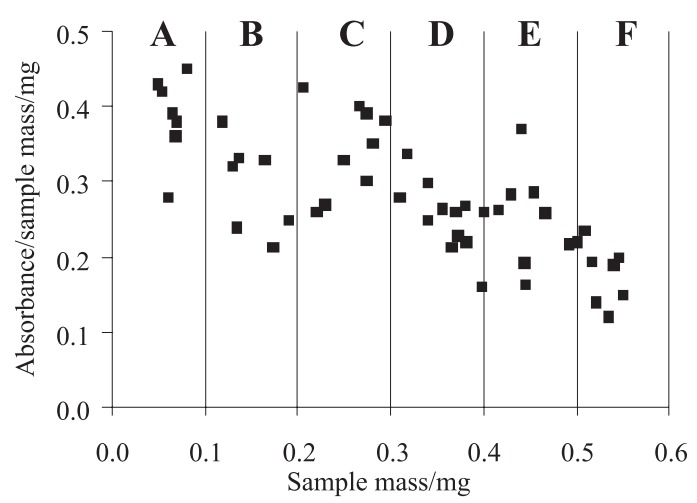

Figure 4. Influence of sample $\left(\mathrm{BaSO}_{4}\right)$ mass on analytical results for As determination by the proposed $\mathrm{D}_{2}$-SoS-ETAAS. Block $\mathrm{A}=0.05$ to $0.09 \mathrm{mg}$; Block $\mathrm{B}=0.10$ to $0.19 \mathrm{mg}$; Block $\mathrm{C}=0.20$ to $0.29 \mathrm{mg}$; Block $\mathrm{D}=0.30$ to $0.39 \mathrm{mg}$; Block $\mathrm{E}=0.40$ to $0.49 \mathrm{mg}$; Block $\mathrm{F}=0.50$ to $0.55 \mathrm{mg}$.

However, in both cases the precision was poor as shown in Figure 4 impairing reliable results using this technique. Therefore, the use of $\mathrm{D}_{2}$-SoS-ETAASS was unreliable for the determination of $\mathrm{As}$ in $\mathrm{BaSO}_{4}$ in the range from 0.05 to $0.55 \mathrm{mg}$.

Table 2. Analysis of variance and Tukey-Kramer test for different blocks in Figures 4 and 5. Results for $\mathrm{D}_{2}$-SoS-ET AAS/Z-SoS-ET AAS

\begin{tabular}{lccccc}
\hline & $\begin{array}{c}\text { Degrees of } \\
\text { freedom }\end{array}$ & $\begin{array}{c}\text { Sum of } \\
\text { squares }\end{array}$ & $\begin{array}{c}\text { Mean } \\
\text { square }\end{array}$ & $F$ test & $p$ value \\
\hline Between & $5 / 7$ & $0.2292 /$ & $0.04584 /$ & $15.634 /$ & $0.0001 /$ \\
groups & & 0.1680 & 0.02400 & 24.711 & 0.0001 \\
Within & $45 / 55$ & $0.1319 /$ & $0.002932 /$ & & \\
groups & & 0.05342 & 0.0009712 & & \\
& & $0.3612 /$ & & & \\
Total & $50 / 62$ & 0.2214 & & & \\
\hline
\end{tabular}

\begin{tabular}{|c|c|c|c|c|c|c|c|c|c|c|c|c|c|c|c|}
\hline \multicolumn{7}{|c|}{$\mathrm{D}_{2}$-SoS-ETAAS } & \multicolumn{9}{|c|}{ Z-SoS-ETAAS } \\
\hline & A & B & $\mathrm{C}$ & D & $\mathrm{E}$ & $\mathrm{F}$ & & A & B & $\mathrm{C}$ & $\mathrm{D}$ & E & $\mathrm{F}$ & G & $\mathrm{H}$ \\
\hline A & + & - & + & - & - & - & A & + & - & - & - & - & - & - & - \\
\hline B & - & + & + & + & + & - & B & - & + & + & + & - & - & - & - \\
\hline $\mathrm{C}$ & + & + & + & - & - & - & $\mathrm{C}$ & - & + & + & + & + & + & + & - \\
\hline D & - & + & - & + & + & + & $\mathrm{D}$ & - & + & + & + & + & + & + & - \\
\hline E & - & + & - & + & + & + & $\mathrm{E}$ & - & - & + & + & + & + & + & - \\
\hline \multirow[t]{3}{*}{$\mathrm{F}$} & - & - & - & + & + & + & $\mathrm{F}$ & - & - & + & + & + & + & + & - \\
\hline & & & & & & & G & - & - & + & + & + & + & + & - \\
\hline & & & & & & & $\mathrm{H}$ & - & - & - & - & - & - & - & + \\
\hline
\end{tabular}

(+) difference not statistically significant (95\%); (-) difference statistically significant $(95 \%)$.

On the other hand, using Z-SoS-ETAAS, barium sulfate masses between 0.05 and $0.8 \mathrm{mg}$ could be used (Figure 5). Nevertheless, for sample masses between 0.05 to $0.2 \mathrm{mg}$ 
overestimated values were obtained. For sample masses higher than $0.7 \mathrm{mg}$ underestimated results were found. From the statistical evaluation (Table 2), sample mass interval was higher than using $\mathrm{D}_{2}$-SoS-ETASS (from $\mathrm{C}$ to G-block). Therefore, sample masses ranging from 0.2 to $0.7 \mathrm{mg}$ were used allowing more consistent results for As determination. Using Z-SoS-ET AAS, the upper limit of mass interval allowed the analysis of relatively higher sample masses when compared to previous work where $\mathrm{BaSO}_{4}$ masses below $0.07 \mathrm{mg}$ were applied. ${ }^{26}$

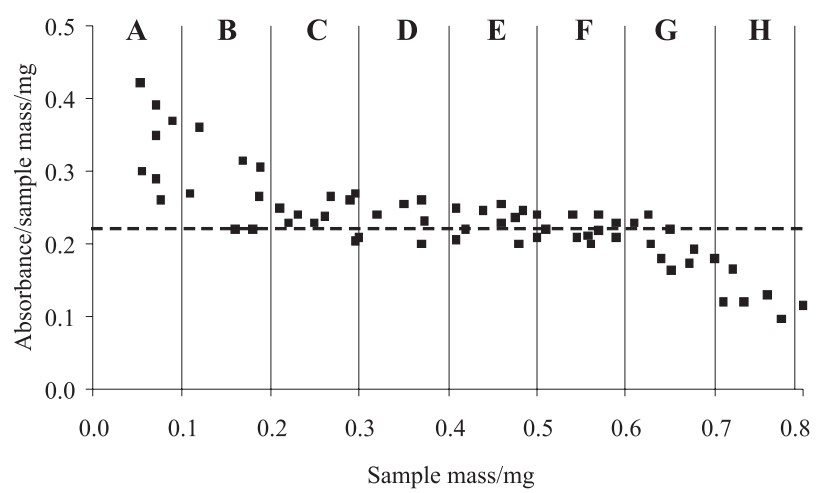

Figure 5. Influence of sample $\left(\mathrm{BaSO}_{4}\right)$ mass on analytical results for As determination by the proposed Z-SoS-ET AAS. Block A $=0.05$ to $0.09 \mathrm{mg}$; Block $\mathrm{B}=0.10$ to $0.19 \mathrm{mg}$; Block $\mathrm{C}=0.20$ to $0.29 \mathrm{mg}$; Block $\mathrm{D}=0.30$ to $0.39 \mathrm{mg}$; Block $\mathrm{E}=0.40$ to $0.49 \mathrm{mg}$; Block $\mathrm{F}=0.50$ to $0.59 \mathrm{mg}$; Block $\mathrm{G}=0.60$ to $0.69 \mathrm{mg}$; Block $\mathrm{H}=0.70$ to $0.80 \mathrm{mg}$. The dashed line shows the mean value of absorbance/sample mass.

\section{Sample analysis and figures of merit}

Optimized conditions for As determination in barium sulfate by Z-SoS-ET AAS are shown in Table 1. Possible incomplete release of $\mathrm{As}$ from $\mathrm{BaSO}_{4}$ matrix during the atomization was evaluated by performing a subsequent application of complete heating program without sample residue removal (the cleanout step was omitted in the first heating cycle). Analytical signals were negligible (less than $0.001 \mathrm{~s}$ ) after application of the second heating cycle. However, in order to prevent eventual memory effects the cleaning step $\left(2600{ }^{\circ} \mathrm{C}\right.$ ) was always applied. Calibration was feasible by using aqueous reference standard solutions. The characteristic mass was $25.4 \mathrm{pg}$ and good linearity was obtained $\left(\mathrm{R}^{2}=0.995\right)$. Limit of detection was $0.005 \mu \mathrm{g} \mathrm{g}^{-1}(3 \sigma, \mathrm{n}=10)$ and relative standard deviation was better than $9.5 \%$ using Z-SoS-ETAAS.

Arsenic concentration in pharmaceutical grade $\mathrm{BaSO}_{4}$ samples ranged from 0.32 to $4.29 \mu \mathrm{g} \mathrm{g}^{-1}$ as shown in Table 3. As no certified reference $\mathrm{BaSO}_{4}$ is available, recovery tests were carried out for the proposed method. Arsenic reference solutions were added to the solid $\mathrm{BaSO}_{4}$ after sample weighing and recoveries were between 96 and $102 \%$. Since recovery tests using reference solutions could not assure the accuracy of procedure, analysis using an independent technique (NAA) was performed for $\mathrm{BaSO}_{4}$ sample "E". Results were not statically different using the proposed procedure or NAA technique.

Solutions obtained after the extraction procedure described in European Pharmacopoeia were analyzed by the recommended procedure by arsine generation ${ }^{2}$ and also by ICP OES and ICP-MS. The procedure described in European Pharmacopoeia was not feasible for the detection of As in all $\mathrm{BaSO}_{4}$ samples. For ICP OES, arsenic concentration for samples $\mathrm{B}$ and $\mathrm{D}$ were below the correspondent LOD $\left(0.8 \mu \mathrm{g} \mathrm{g}^{-1}\right)$. However, results for samples A and C using ICP OES and ICP-MS were around $20 \%$ below those by using the proposed Z-SoS-ET AAS method. These results were due to the low extraction efficiency and/or analyte losses during the extraction step (dried residue after extraction was analysed and As was determined by the proposed SoS-ET AAS procedure). Contrarily to results obtained using the proposed method the blank values for digests after extraction described in European Pharmacopoeia were relatively higher. ${ }^{2}$ This aspect can be considered as an advantage for the proposed method where integrated absorbance values for blanks were always lower than $0.001 \mathrm{~s}$.

It is well known that particle size and the homogenous distribution of the analyte in solid samples could influence both the accuracy and the relative standard deviation in determinations by SoS-ET AAS. ${ }^{26}$ For samples investigated in the present work, more than $95 \%$ of particles were smaller than $30 \mu \mathrm{m}$. This low particle size can explain

Table 3. Results for the determination of arsenic in barium sulfate by the proposed Z-SoS-ET AAS procedure (values in $\mu \mathrm{g} \mathrm{g}{ }^{-1}$ with mean and standard deviation), by ICP-MS and ICP OES after extraction $(n=7)$ and by NAA

\begin{tabular}{lcccc}
\hline Samples & Z-SoS-ET AAS & ICP OES & ICP-MS & NAA \\
\hline A & $1.17 \pm 0.05$ & $0.93 \pm 0.14^{\mathrm{a}}$ & $0.98 \pm 0.17^{\mathrm{a}}$ & - \\
B & $0.51 \pm 0.04$ & $<0.8$ & $0.37 \pm 0.07^{\mathrm{b}}$ & - \\
C & $1.18 \pm 0.09$ & $0.89 \pm 0.16^{\mathrm{a}}$ & $0.95 \pm 0.20^{\mathrm{a}}$ & - \\
D & $0.32 \pm 0.03$ & $<0.8$ & $0.26 \pm 0.06^{\mathrm{b}}$ & - \\
E & $4.29 \pm 0.11$ & $3.44 \pm 0.60^{\mathrm{b}}$ & $3.58 \pm 0.47^{\mathrm{b}}$ & $4.34 \pm 0.03$ \\
\hline
\end{tabular}

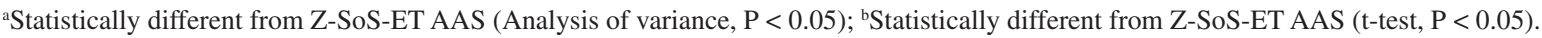


partially the relatively low values for standard deviation obtained in this work as shown in Table 3.

\section{Conclusions}

Arsenic determination by ICP OES and ICP-MS and also the application of the limit test proposed by current pharmacopoeias require a previous sample preparation step that involves the use of corrosive and hazardous chemicals. The recommended procedure in pharmacopeias is time consuming and could introduce a source of contamination in the digestion step.

The proposed method by Z-SoS-ET AAS presented good accuracy and precision. Moreover, using optimized temperature parameters, including the use of palladium as chemical modifier and hydrogen introduction in the graphite tube during the pyrolysis step, it was possible to minimize the matrix effects for suitable As determination. In special, the use of $\mathrm{H}_{2}$ was important to minimize the BG preventing the occurrence of overcorrection problems. In addition, calibration using aqueous reference standard solutions was feasible, avoiding the necessity of solid certified reference materials, as observed for previous works using SoS-ET AAS for a similar matrix. ${ }^{26}$ Furthermore, in the proposed method, the absence of a sample preparation step minimizes the use of chemical reagents and allows the reduction of the analysis time to about $10 \mathrm{~min}$ for one sample.

\section{Acknowledgments}

Authors are grateful to $\mathrm{CNPq}$ (Instituto Nacional de Ciência e Tecnologia de Bioanalítica, Proc. No. 573672/2008-3), CAPES and Agência Nacional de Vigilância Sanitária (ANVISA-Brazil).

\section{References}

1. The United States Pharmacopoeia, USP 30, The United States Pharmacopeial Convention, Rockville, 2007.

2. European Pharmacopoeia, $5^{\text {th }}$ ed., Council of Europe, Strasbourg, France, 2005

3. Hughes, M. F.; Toxicol. Lett. 2002, 133, 1.

4. Nriagu, J. O.; Arsenic in the Environment, Part II, Human Health and Ecosystem Effects, John Wiley \& Sons, Inc.: New York, 1994.

5. National Research Council, Arsenic in Drinking Water, National Academy Press: Washington, DC, 1999.

6. Smith, A. H.; Lingas, E. O.; Rahman, M.; Bull. World Health Organ. 2000, 78, 1093.

7. Viitak, A.; Volynsky, A. B.; Talanta 2006, 70, 890.

8. Volynsky, A. B.; Wennrich, R.; Talanta 2003, 59, 277.
9. Vale, M. G. R.; Oleszczuk, N.; dos Santos, W. N. L.; Appl. Spectrosc. Rev. 2006, 41, 377.

10. Dong, H. M.; Krivan, V.; Welz, B.; Schlemmer, G.; Spectrochim. Acta, Part B 1997, 52, 1747.

11. Dong, H. M.; Krivan, V.; Spectrochim. Acta, Part B 2001, 56, 1645.

12. Welz, B.; Spectrochim. Acta, Part B 1999, 54, 2081.

13. Resano, M.; Briceño, J.; Aramendía, M.; Belarra, M. A.; Anal. Chim. Acta 2007, 582, 214.

14. Mattos, J. C. P.; Flores, E. M. M.; Krivan, V.; J. Anal. At. Spectrom. 2008, 23, 931.

15. Nomura, C. S.; Silva, C. S.; Nogueira, A. R. A.; Oliveira, P. V.; Spectrochim. Acta, Part B 2005, 60, 673.

16. Belarra, M. A.; Resano, M.; Vanhaecke, F.; Moens, L.; Trends Anal. Chem. 2002, 21, 828.

17. Volynsky, A. B.; Stakheev, A. Y.; Telegina, N. S.; Senin, V. G.; Kustov, L. M.; Wennrich, R.; Spectrochim. Acta, Part B 2001, 56, 1387.

18. Welz, B.; Bozsai, G.; Sperling, M.; Radziuk, B.; J. Anal. At. Spectrom. 1992, 7, 505.

19. Katskov, D. A.; Lemme, M.; Tittarelli, P.; Spectrochim. Acta, Part B 2004, 59, 101

20. Lemme, M.; D. Katskov, A.; Tittarelli, P.; Spectrochim. Acta, Part B 2004, 59, 115.

21. Heitmann, U.; Schütz, M.; Becker-Ross, H.; Florek, S.; Spectrochim. Acta, Part B 1996, 51, 1095.

22. Qiao, H.; Parsons, P. J.; Slavin, W.; Clin. Chem. 1995, 41, 1451.

23. Kruger, P. C.; Parsons, P. J.; Spectrochim. Acta, Part B 2007, 62, 288.

24. Hornung, M.; Krivan, V.; Spectrochim. Acta, Part B 1999, 54, 1177.

25. L’vov, B. V.; Spectrochim. Acta, Part B 1997, 52, 1.

26. Nowka, R.; Marr, I. L.; Ansari, T. M.; Muller, H.; Fresenius J. Anal. Chem. 1999, 364, 533.

27. Bermejo-Barrera, P.; Moreda-Pineiro, J.; Moreda-Pineiro, A.; Bermejo-Barrera, A.; J. Anal. At. Spectrom. 1998, 13, 777.

28. Belarra, M. A.; Crespo, C.; Martínez-Garbayo, M. P.; Castillo, J. R.; Spectrochim. Acta, Part B 1997, 52, 1855.

29. Zhe-Ming, N.; Xiao-Quan, S.; Spectrochim. Acta, Part B 1987, 42, 937.

30. Bolzan, R. C.; Rodrigues, L. F.; de Mattos, J. C. P.; Dressler, V. L.; Flores, E. M. M.; Talanta 2007, 74, 119.

31. Mohazzabi, E.; Searcy, A. W.; J. Chem. Soc., Faraday Trans. 1976, 72,290 .

32. L'vov, B. V.; Novichikhin, A. V.; Thermochim. Acta 1997, 290, 239.

33. Castro, M. A.; Faulds, K.; Smith, W. E.; Aller, A. J.; Littlejohn, D.; Spectrochim. Acta, Part B 2004, 59, 827.

34. Voth-Beach, L. M.; Shrader, D. E.; J. Anal. At. Spectrom. 1987, 2, 45.

35. Volynsky, A. B.; Spectrochim. Acta, Part B 2004, 59, 1799.

Received: February 27. 2009

Web Release Date: December 21, 2009 